GRASAS Y ACEITES 68 (4)

October-December 2017, e219

ISSN-L: 0017-3495

doi: http://dx.doi.org/10.3989/gya.0332171

\title{
Predicting extra virgin olive oil freshness during storage by fluorescence spectroscopy
}

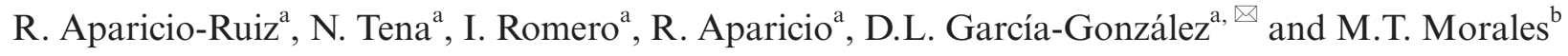 \\ ${ }^{a}$ Instituto de la Grasa (CSIC), Bdg. 46 Campus University Pablo de Olavide, E-41013 Seville, Spain \\ ${ }^{b}$ Department of Analytical Chemistry, Universidad de Sevilla, Prof. García González, 2, 41012, Seville, Spain \\ ${ }^{凶}$ Corresponding author: dlgarcia@ig.csic.es
}

Submitted: 13 March 2017; Accepted: 11 July 2017

\begin{abstract}
SUMMARY: Virgin olive oil quality relates to flavor and unique health benefits. Some of these properties are at the most desirable level when the oil is just extracted, since it is not a product that improves with age. On the contrary, the concentrations of many compounds change during its shelf-life. These changes reveal the aging of the oil but do not necessarily mean decay in sensory properties, so in some cases an aged oil from healthy olives may be better qualified than a fresh one from olives affected by fermentation. The aim of this work is to analyze different methodologies proposed for assessing the quality of virgin olive oil with implications in freshness and aging of the oil, and to highlight the possibilities of rapid spectrofluorimetric techniques for assessing oil freshness by checking the evolution of pigments during storage. The observed change in the selected spectral features and mathematical modelling over time was compared with the accepted model for predicting the amount of pyropheophytin a, which is based on isokinetic studies. The best regression was obtained for $655 \mathrm{~nm}$ (adjusted$\mathrm{R}^{2}=0.91$ ) wavelength, which matches the distinctive band of pigments. The two mathematical models described in this study highlight the usefulness of pigments in the prediction of the shelf-life of extra virgin olive oil.
\end{abstract}

KEYWORDS: Freshness; Pigments; Pyropheophytin; Spectrofluorimetry; Virgin olive oil

RESUMEN: Predicción de la frescura del aceite de oliva virgen extra durante el almacenamiento mediante espectroscopía de fluorescencia. La calidad del aceite de oliva virgen está relacionada con su flavor y sus beneficios únicos para la salud. Algunas de estas propiedades se encuentran en el nivel más deseable cuando el aceite está recién extraído, ya que no es un producto que mejore con el tiempo. Por el contrario, las concentraciones de muchos compuestos cambian a lo largo de la vida útil. Estos cambios revelan el envejecimiento del aceite, pero no implican necesariamente la alteración de las propiedades sensoriales, por lo que en algunos casos un aceite envejecido procedente de aceitunas sanas puede presentar mejor calidad que uno fresco procedente de aceitunas afectadas por procesos de fermentación. El objetivo de este trabajo es estudiar diferentes metodologías propuestas para evaluar la calidad del aceite de oliva virgen con implicaciones en la frescura y el envejecimiento del aceite, destacando las posibilidades de las rápidas técnicas espectrofluorométricas para evaluar la frescura del aceite verificando la evolución de los pigmentos durante el almacenamiento. El cambio observado en las características espectrales seleccionadas y su modelado matemático a lo largo del tiempo se comparó con el modelo aceptado para predecir la cantidad de pirofeofitina a, que se basa en estudios isocinéticos. Los dos modelos matemáticos descritos en este estudio pusieron de manifiesto la utilidad de los pigmentos en la predicción de la vida útil del aceite de oliva virgen extra. La mejor regresión se obtuvo para $655 \mathrm{~nm}\left(\mathrm{R}^{2}\right.$-ajustado $\left.=0,91\right)$, longitud de onda que coincide con la banda distintiva de pigmentos.

PALABRAS CLAVE: Aceite de oliva virgen; Espectrofluorimetría; Frescura; Pigmentos; Pirofeofitina

ORCID ID: Aparicio-Ruiz R https://orcid.org/0000-0003-1093-1928, Tena N https://orcid.org/0000-0003-0933-5192, Romero I https://orcid.org/0000-0003-3811-1577, Aparicio R https://orcid.org/0000-0001-5538-4433, García-González DL https://orcid.org/0000-0003-0735-8470, Morales MT https://orcid.org/0000-0001-7058-4433

Citation/Cómo citar este artículo: Aparicio-Ruiz R, Tena N, Romero I, Aparicio R, García-González DL, Morales MT. 2017. Predicting extra virgin olive oil freshness during storage by fluorescence spectroscopy. Grasas Aceites 68 (4), e219. http://dx.doi.org/10.3989/gya.0332171

Copyright: (02017 CSIC. This is an open-access article distributed under the terms of the Creative Commons Attribution (CC-by) Spain 3.0 License. 


\section{INTRODUCTION}

Virgin olive oil (VOO) sensory quality is related to its flavor, which decisively influences consumer preferences, and its unique health benefits explained by its content in phenols and monounsaturated fatty acids. Some of these properties are found at the most desirable level just after the oil extraction. Unlike other food products, virgin olive oil is not a product that improves with age. Thus, a given sample of virgin olive oil undergoes chemical processes that negatively affect its properties during its shelf-life. The decay in functional or quality properties during aging is related to oxidative processes (Morales and Przybylski, 2013), and thereby the concentration of these compounds evolves depending on the concentration of antioxidant compounds of the initial oil and the storage conditions from the olive mill to the kitchen.

Many compounds which change in their concentrations during VOO shelf-life reveal the aging of the oil but they do not necessarily imply decay in aroma or taste properties. In fact, sometimes an aged oil may have better sensory quality than a fresh one obtained from damaged olives and still be within the extra-VOO category, and thereby freshness and sensory quality should not be confused, as commonly happens among retailers and consumers (Aparicio-Ruiz et al., 2014). However, freshness had become a parameter of paramount importance to maintain the quality at the highest standard levels until reaching the date indicated in "Best Before" though freshness is not necessarily related to VOO sensory quality (Aparicio-Ruiz et al., 2014). For this reason, methodologies to assess the freshness of oil should be separated from those which evaluate sensory quality (e.g. panel tests or volatile compound analysis) (IOC, 2015). Consequently, the concept of freshness, which is intuitively associated with the time from VOO processing, should be measured with chemical compounds that do not mislead to underestimations or overestimations of virgin olive oils of good quality.

Table 1 shows a summary of some methods proposed for assessing the quality parameters of virgin olive oils that have implications in freshness, aging and sensory parameters of oils. The instrumental approaches qualifying the oils into higher/lower grades that also assess freshness can be grouped in two groups: those that have a causal relationship with sensory quality, and those that have a casual relationship (Aparicio et al., 2012). The latter methods analyze compounds whose concentrations are mathematically correlated with freshness or some sensory parameters. Mathematical correlation, however, can fail in providing a full explanation of freshness/ quality under certain circumstances, and in those cases, sensory and chemical information would be dissociated. Among the compounds that have been suggested for tracing the aging of virgin olive oils, pigments have been proposed as promising markers (Aparicio-Ruiz et al., 2012). Thus, a recently obtained VOO contains lutein, $\beta$-carotene, chlorophyll $(\mathrm{a}, \mathrm{b})$ and pheophytin $(\mathrm{a}, \mathrm{b})$ as major pigments and it does not contain pyropheophytin a (Mínguez-Mosquera et al., 1990). The pigment profile varies during VOO storage, even under ideal darkness and controlled temperature conditions (Gallardo Guerrero et al., 2005), because of pigment degradation reactions (e.g. pheophytinization of chlorophylls) (Aparicio-Ruiz et al., 2010), which start at the malaxation process of crushed olives. The degradation process continues during the storage of VOOs until the formation of pyropheophytin from pheophytin due to the loss of the carbomethoxy group in the $\mathrm{C} 13$ of the isocyclic ring of the chlorophyll structure. The former compound, pyropheophytin, should be present at low levels in recently obtained oils, and hence it has been suggested as a useful parameter for monitoring the degradation of VOO (Aparicio-Ruiz et al., 2010) during storage. Thus, a high concentration of pyropheophytin can be due to inadequate conditions of temperature during the storage of VOOs. The relationship between pyropheophytins and storage conditions has awakened an interest in studying the formation kinetics of this compound with the aim of establishing a prediction model (Aparicio-Ruiz et al., 2012) for determining the shelf-life of VOOs, taking into account the temperature in the place where the oil is sold.

The determination of pyropheophytins as an indirect measurement of extra virgin olive oil (EVOO) freshness can be accepted under the premise that freshness highly depends on the storage conditions and not only on the time elapsed since olives were harvested, as consumers are inclined to think. Thus, researchers have tried to demonstrate the usefulness of pigments for the assessment of EVOO freshness (Ayton et al., 2012; Aparicio-Ruiz et al., 2012). This analytical determination is particularly interesting if the initial value of pyropheophytins is provided, because it would allow for detecting inadequate storage conditions (Aparicio-Ruiz et al., 2012). Therefore, pyropheophytins can be used to carry out a backward trace of the storage conditions of VOOs by checking the differences between the initial concentrations with the values at any moment. The rising interest in pigments for freshness assessment of VOOs has led to the requirement of a major perfection in their analytical determinations, in particular in those that allow a rapid measurement. The use of fluorescence spectroscopy is favoring the development of routine analysis of pigments. In fact, this technique has been used for studies of stress processes and physiological changes in plants (De Ell and Toivonen, 
TABLE 1. Summary of the characteristics of analytical methodologies proposed for assessing the quality of virgin olive oil with implications in freshness, aging and sensory parameters of oils (adapted from Aparicio et al., 2012).

\begin{tabular}{|c|c|c|c|}
\hline Analyte(s) & Technique & Relationship $^{a}$ & Comments \\
\hline Pyropheophytin a & Chromatography & Casual & $\begin{array}{l}\text { Compounds not directly related to rancidity and shelf-life. } \\
\text { The evolution of pyropheophytins can be predicted with } \\
\text { kinetics models. }\end{array}$ \\
\hline Hydroperoxides & $\begin{array}{l}\text { Titration } \\
\text { (Peroxide value) }\end{array}$ & Causal/Casual & $\begin{array}{l}\text { Causal relationship for rancidity (oxidation) and casual } \\
\text { for the rest of the attributes. } \\
\text { There are legal limits. }\end{array}$ \\
\hline Diacylglycerols & Chromatography & Apparently Causal & $\begin{array}{l}\text { No direct relationship with either positive or negative } \\
\text { attributes. } \\
\text { Information on hydrolysis reactions. }\end{array}$ \\
\hline Phenols & Chromatography & Causal & $\begin{array}{l}\text { It is not fully known which phenol compounds are the } \\
\text { main contributors to bitterness/pungency. } \\
\text { Bitterness can accurately be explained by total phenols. }\end{array}$ \\
\hline $\begin{array}{l}\text { Volatiles } \\
\text { (total content) }\end{array}$ & $\begin{array}{l}\text { Electronic nose } \\
\text { (sensors) / IMS } \\
\text { (Ion Mobility } \\
\text { Spectrometry) }\end{array}$ & Causal & $\begin{array}{l}\text { The total concentration of volatiles can be associated with } \\
\text { different defects. } \\
\text { The direct injection of volatiles may cause problems of } \\
\text { low sensitivity. } \\
\text { It is a rapid and non-destructive technique. }\end{array}$ \\
\hline $\begin{array}{l}\text { Volatiles (individual } \\
\text { composition) }\end{array}$ & Chromatography & Causal & $\begin{array}{l}\text { Markers for common sensory defects were previously } \\
\text { selected, and their odor thresholds and their maximum } \\
\text { and average concentrations are known. } \\
\text { Interpretation of chromatograms requires prior training. }\end{array}$ \\
\hline
\end{tabular}

${ }^{a}$ Relationship with sensory quality as perceived by panellists and consumers.

1999) and in tracking thermo-oxidative processes in edible oils (Tena et al., 2009; Tena et al., 2012) among other applications.

The present work is focused on checking the evolution of pigments during VOO storage, firstly by applying a mathematical model to evaluate the changes in pigment contents during the storage of virgin olive oil in supermarkets; and secondly, by selecting the fluorescence bands associated to aging in order to design a mathematical model for assessing the freshness of EVOO as a possible alternative to the determination of pyrophenophitins.

\section{MATERIALS AND METHODS}

\subsection{Samples}

Experiments were carried out with two extra virgin olive oils (EVOO) that were stored for 18 months, which is the most common shelf-life for EVOOs. First oil was a mixture 1:1 of two VOO varieties (Picual and Lechín) with the following quality parameters: organoleptic assessment: $8.3 \pm$ 0.4 (median of fruitiness, $\mathrm{Mf}$ ); peroxide value: 2.87 ( $\mathrm{mEq} \mathrm{O} / 2 / \mathrm{kg})$; acidity: $0.19(\% \mathrm{~m} / \mathrm{m}$ of oleic acid); K270: $0.08\left(K_{1 \mathrm{~cm}}^{1 \%}\right)$; and K232: $1.95\left(K_{1 \mathrm{~cm}}^{1 \%}\right)$. The second virgin olive oil was an extra virgin olive oil var. Hojiblanca with the following characteristics: 8.0 \pm 0.5 (median of fruitiness, Mf); peroxide value: $2.95(\mathrm{mEq} \mathrm{O} / 2 / \mathrm{kg}$ ); acidity: $0.21(\% \mathrm{~m} / \mathrm{m}$ of oleic acid); K270: $0.10\left(K_{1 \mathrm{~cm}}^{1 \%}\right)$; and $\mathrm{K} 232: 1.98\left(K_{1 \mathrm{~cm}}^{1 \%}\right)$.
Each virgin olive oil was stored in eighteen $100 \mathrm{~mL}$ sealed flasks, each one corresponding to one of the months in the shelf-life study. The flasks were colored and they were filled with oil to the top to avoid any headspace. The flasks were stored at room temperature (indoors) in a cabinet under controlled light conditions. The oils were sampled every month, which means 18 samples for each oil.

\subsection{Quality parameters}

All quality parameters were determined according to the methods described by the International Organization for Standardization (ISO). For acidity determination (ISO, 2009), 20 $\mathrm{g}$ of oil were weighed in an Erlenmeyer flask of $250 \mathrm{~mL}$. A solution of $100 \mathrm{~mL}$ of ethanol/ethyl ether (50:50), previously neutralized, and phenolphthalein solution were added to the Erlenmeyer flask. The mixture was titrated with a $\mathrm{NaOH} 0.1 \mathrm{M}$ solution.

The UV extinction coefficients were determined by measuring the absorbance of the oil, previously dissolved in cyclohexane at their respected concentration, at $232 \mathrm{~nm}$ and $270 \mathrm{~nm}$. The results were expressed as extinction coefficients (K232 and K270) by applying the equations described in regulation ISO 3656 (ISO, 2011).

The peroxide value was determined by titration according to ISO 3960 (ISO, 2007). A mixture of 2 $\mathrm{g}$ of sample, $10 \mathrm{~mL}$ of choloroform, $15 \mathrm{~mL}$ of acetic 
acid and $1 \mathrm{~mL}$ of a saturated IK solution were prepared in a flask. After $30 \mathrm{~s}$ shaking, the flask was left in the dark for 5 minutes. The mixture was titrated with sodium tiosulphate $0.002 \mathrm{~N}$ after adding $75 \mathrm{~mL}$ distilled water to stop the reaction and a starch solution as indicator. The results were expressed in $\mathrm{mEq}$ $\mathrm{O}_{2} / \mathrm{kg}$.

\subsection{Analysis of pigments}

\subsubsection{Chromatography}

The determination of pigments (chlorophylls, pheophytins and pyropheophytin a) was carried out with a HPLC (Agilent Technologies 1100, Santa Clara, California) equipped with a C18-RF Spherisorb ODS-2 $(25 \mathrm{~cm} \times 4 \mathrm{~mm}$ i.d., $3 \mu \mathrm{m}$ particle size) (Waters, Saint Quentin-Ylines, France) and a diode array detector. It worked in gradient regime using the solvents (A) water/ion-pair reagent/methanol $(1: 1: 8, \mathrm{v} / \mathrm{v} / \mathrm{v})$ and (B) acetone/methanol (1:1 $\mathrm{v} / \mathrm{v}$ ), at a flow rate of $1.25 \mathrm{~mL} / \mathrm{min}$. The ion-pair reagent was $0.05 \mathrm{M}$ tetrabutylammonium acetate and $1 \mathrm{M}$ ammonium acetate in water (AparicioRuiz et al., 2010). The chromatographic signals were obtained at $410 \mathrm{~nm}$ (pheophytin a and pyropheophytin a), $430 \mathrm{~nm}$ (chlorophyll a, pheophytin b and pyropheophytin b) and $450 \mathrm{~nm}$ (chlorophyll b). Sample pre-treatment and quantification were carried out by applying the method already described by Tena et al., (2012).

The standard of chlorophyll a, from spinach, was bought from Sigma-Aldrich (C5753) according to the suggestion of Gertz and Fiebig (2006). Pheophytin was obtained by acidification with hydrochloric acid from the chlorophylls (Sievers and Hynninem, 1977). Pyropheophytin a was obtained from pheophytin a by thermal treatment with pyridine for $24 \mathrm{~h}$ at $100{ }^{\circ} \mathrm{C}$ with reflux (Schwartz et al., 1981).

\subsubsection{Fluorescence spectroscopy}

Spectrofluorimetric measurements were performed with a RF-1501 Shimadzu spectrofluorophotometer (Shimadzu Corporation, Kyoto, Japan) equipped with a continuous $150 \mathrm{~W}$ xenon lamp, excitation and emission monochromators, and a photomultiplier detector. Fluorescence emission spectra $(360-900 \mathrm{~nm}, 1 \mathrm{~nm}$ interval) were collected at $350 \mathrm{~nm}$ excitation wavelength (Zandomeneghi et al., 2005), slits were set at 10 $\mathrm{nm}$. The samples were scanned using a $3 \mathrm{~mL}$ nonfluorescent cell $(10 \mathrm{~mm}$ path length). After each series of measurements, the cuvette was cleaned using detergent, followed by a rinse with de-ionized hot water and acetone to dry and eliminate the rest of the fat. Each sample was analyzed in triplicate.

\subsubsection{Mathematical model to predict the percentage of pyropheophytin a}

The mathematical model (Know-How, Utility model, MIT_TO-0022272) that allows predicting the percentage of pyropheophytin a (henceforth, PPP) in EVOOs stored at any given temperature in darkness and with lack of oxygen (Aparicio-Ruiz et al., 2012) was used to evaluate how \% PPP values of samples that are stored in different supermarkets around the world vary over time.

\subsubsection{Statistical Analysis}

Univariate and multivariate algorithms have been applied by means of Statistica version 6.0 (Statsoft, Tulsa, OK). The Brown-Forsythe test was used with the one-way ANOVA to determine the emission wavelengths of the fluorescence spectra obtained for a $\lambda_{\text {ex }}=350 \mathrm{~nm}$ that better correlated with the storage time. Stepwise linear regression analysis (SLRA), with a priori F-to-enter and F-to-remove values, was the statistical procedure used to ensure the significance of the results and to avoid good results by chance. The F-to-enter/remove values (6.14/6.13) were selected under the strictest conditions (Fisher distribution table at $\mathrm{p}=0.05$ ).

\section{RESULTS AND DISCUSSION}

The current trade standard of the International Olive Council (IOC) establishes the criteria, and their limits, for each category of olive oil (IOC, 2016). Three of these parameters are free acidity, peroxide value and absorbance in ultra-violet. Figure 1 shows the trend of those quality parameters during the entire period of the experiment (18 months). All the parameters underwent an increment in their values, with the exception of the peroxide value, although they were always below the limit for extra-virgin olive oil category.

With respect to the presence of pigments, the chromatographic results from quantifying PPP and chlorophylls ( $\mathrm{a}$ and $\mathrm{b}$ ) showed opposite behavior (Figure 2) as the amount of the PPP increased during the experiment, exponentially during the summer time (June, July and August); while the concentration of chlorophylls diminished according to a non-linear equation as well. The change in the concentrations of both compounds has a chemical explanation since an external source of energy (mostly heat but also light) which affects EVOO for a period of time causes decarbomethoxylation of the $\mathrm{C} 13$ carbon of chlorophylls, forming the pyro derivatives (Aparicio Ruiz et al., 2010).

With respect to the fluorescence spectra of the samples, the existence of bands is due to the conjugated structure of the tetrapyrrole-macrocycle, which has been described by different authors (Galeano Díaz et al., 2003; Sikorska et al., 2005; 
(a)

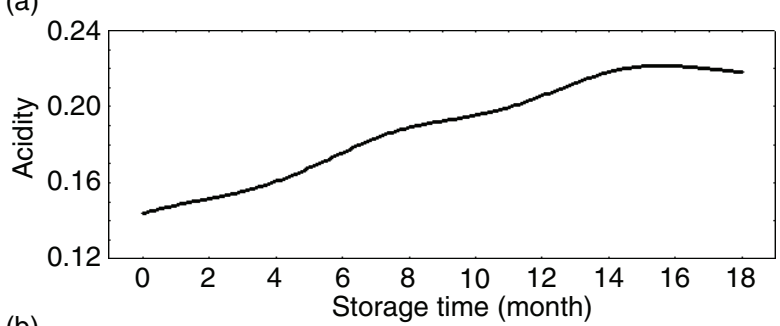

(b)
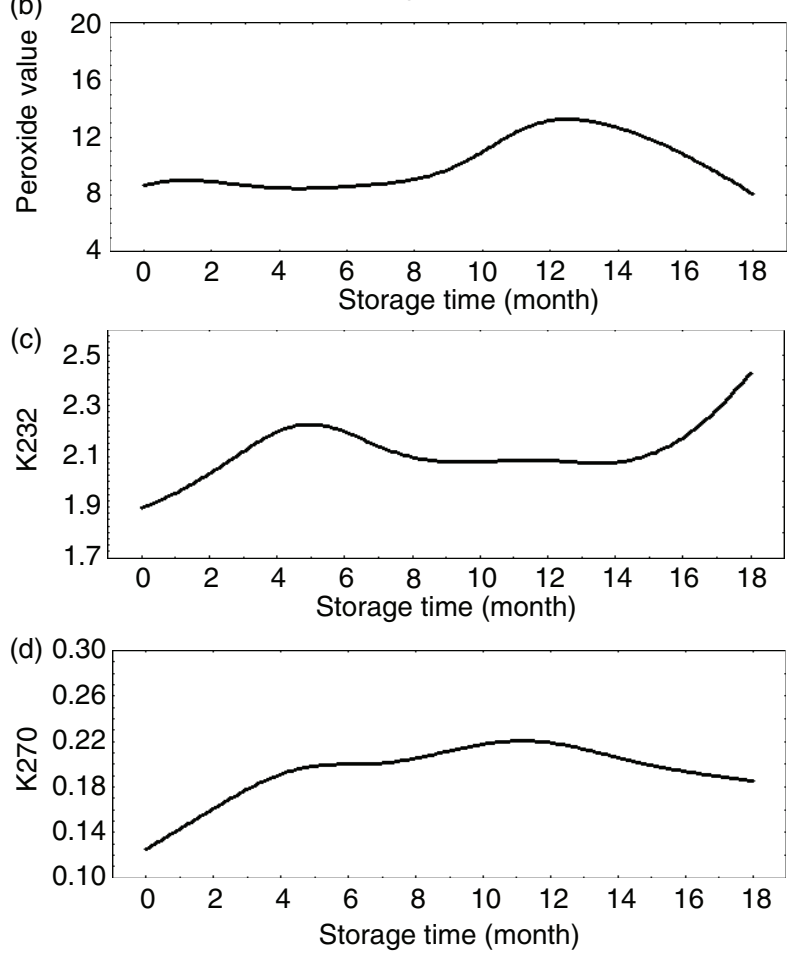

Figure 1. Evolution of quality parameters during the 18 months of the experiment (var. Hojiblanca): (a) acidity $\left(\% \mathrm{~m} / \mathrm{m}\right.$ of oleic acid), (b) peroxide value $\left(\mathrm{mEq} \mathrm{O}_{2} / \mathrm{kg}\right)$, (c) $\mathrm{K} 232\left(K_{1 \mathrm{~cm}}^{1 \%}\right)$ and (d) $\mathrm{K} 270\left(K_{1 \mathrm{~cm}}^{1 \%}\right)$.

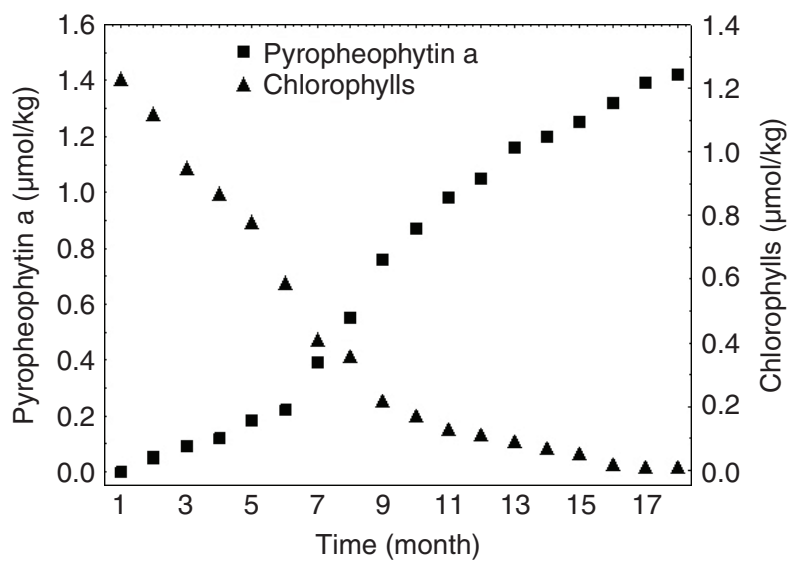

Figure 2. Evolution of the concentrations of chlorophylls and pyropheophytins during the entire experiment of 18 months starting in January (var. Hojiblanca).
Sayago et al., 2007; Tena et al., 2012). In order to verify the spectral assignments to chlorophylls, a purified extract of these compounds was analyzed by fluorescence spectroscopy. Figure 3 shows the emission spectrum at $\lambda_{\mathrm{ex}}=350 \mathrm{~nm}$ of an extract of chlorophyll a from spinach and pheophytins obtained from the chlorophylls by acidification. The only band $\left(\lambda_{\mathrm{em}}=650-700 \mathrm{~nm}\right)$ has already been described by different authors (Dupuy et al., 2005; Zandomeneghi et al.,2005; Sikorska et al., 2005) as caused by the presence of chlorophylls and pheophytins in oils, while other authors (Galeano Díaz et al., 2003) have associated the wavelengths at $669 \mathrm{~nm}$ and $653 \mathrm{~nm}$ with chlorophylls a and $\mathrm{b}$, respectively.

Figure 4 shows the emission spectrum of 8 samples which range over the eighteen months of the experiment. Six main bands at around 480, 510, 530, 560,660 and $680 \mathrm{~nm}$ characterize the virgin olive oil at the initial state of the shelf-life study. The profile of the initial olive oil in the range of wavelengths associated with pigments, chlorophylls and pheophytins, resembles the fluorescence spectra obtained with the chlorophyll extract (Figure 3). It is noticeable that the band around $625 \mathrm{~nm}$ disappeared before the fourth month of the experiment, which agrees with results obtained in a previous study centered on thermoxidation, where chlorophylls disappeared at the beginning of the experiment (Tena, 2010).

Brown-Forsythe univariate algorithm showed the best p-values $(<0.05)$ between the fluorescence spectral ranges and the contents of PPP and chlorophylls determined by HPLC. Selected bands showed good correlations between data from pigments $(\mu \mathrm{mol} / \mathrm{kg})$ and fluorescence bands (intensity). The bands assigned to pigments $(650-695 \mathrm{~nm})$ showed a high negative correlation with $\mathrm{PPP}(-0.87)$, while the band at $680 \mathrm{~nm}$, previously observed in the spectrum of the purified chlorophyll extracted from spinach

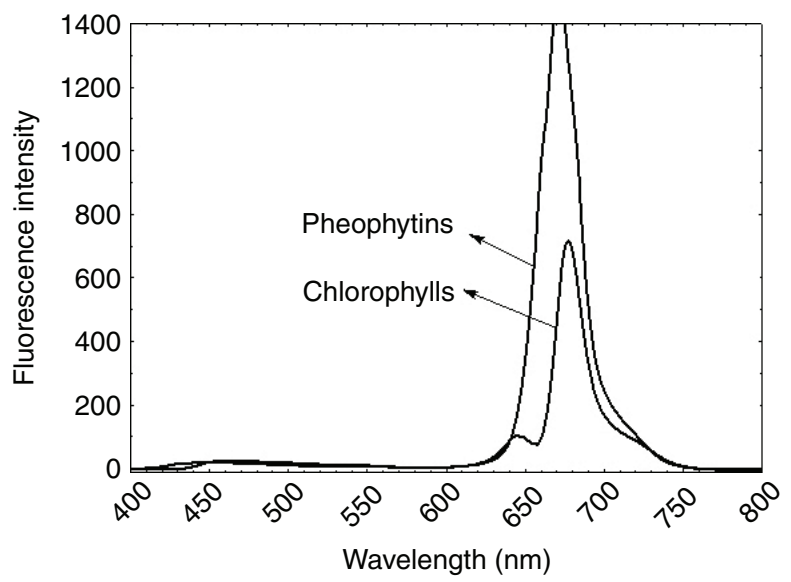

FIGURE 3. Emission spectrum at $\lambda_{\mathrm{ex}}=350 \mathrm{~nm}$ of the standard of chlorophylls extracted from spinach, and the pheophytin obtained from chlorophylls after an acidification process. 


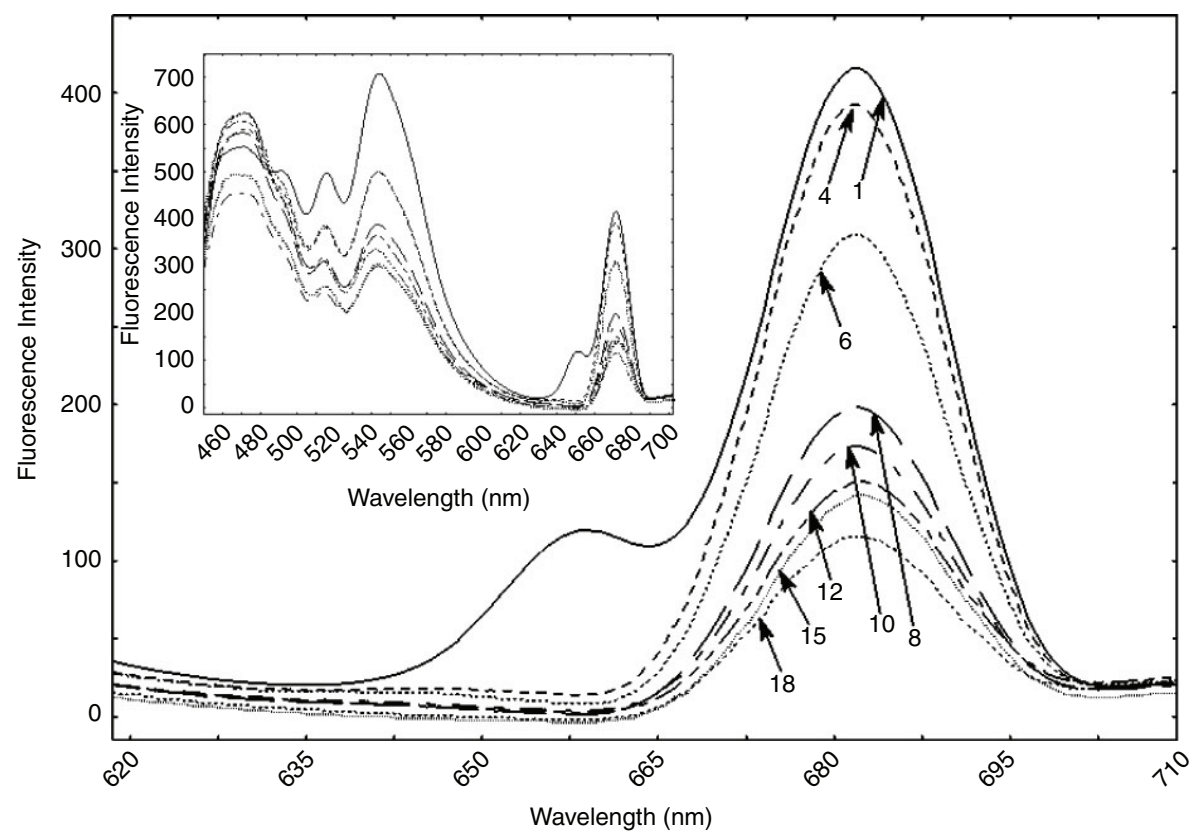

FIGURE 4. Fluorescence spectra of eight virgin olive oil samples that range over the whole experiment of eighteen months of var. Hojiblanca at $\lambda_{\mathrm{ex}}=350 \mathrm{~nm}$. The numbers in the spectra correspond to the month order during the experiment. The inserted figure shows the spectra from $400 \mathrm{~nm}$ to $700 \mathrm{~nm}$ for an ample vision of the fluorescence resulting spectra.

(Figure 3), showed a high positive correlation with the total chlorophylls a and $\mathrm{b}(0.90)$.

Once the oils were analyzed by fluorescence spectroscopy and the bands associated to pigments were identified, the study was centered on: (i) evaluating the pigment (PPP) evolution over time by means of a mathematical model based on kinetics according to the temperature of storage and the initial concentration of PPP (Aparicio et al., 2012), (ii) the selection of fluorescence bands associated to aging and the design of a mathematical model to assess the freshness of the oil.

\subsection{Mathematical modelling of the concentration of pigments over time (influence of temperature)}

Previous studies on the kinetics of pigment degradation resulted in a mathematical model to describe the changes in PPP in EVOOs depending on time and storage temperature under conditions of darkness and lack of oxygen (Aparicio-Ruiz et al., 2012). The results of this estimation can be applied to optimize the storage conditions or to determine the "Best-before" date for a particular geographical location where the oil is being distributed and stored (Aparicio Ruiz et al., 2014).

On the other hand, the degradation of the chlorophylls present in a just obtained EVOO to PPP during its inevitable storage period has been studied with enough scientific base as to regulate that EVOOs must have \% PPP lower than $17 \%$ during their entire shelf-life (CDFA, 2016; SANS, 2015; AS, 2011).

Considering that limit, the proposed prediction model can calculate the time that it takes an EVOO stored under certain conditions of temperature (with information from hourly to yearly temperature average) in exceeding this limit and therefore its "Best before" (or shelf-life) date as EVOO. In order to develop an application of this kinetics model, we have analyzed two hypothetical situations. The first one is the case of an EVOO that is on the shelf of a supermarket situated in Sacramento (California, USA). The other situation corresponds to an EVOO in similar circumstances but located in Frankfurt (Germany). Since the mathematical equation to emulate the formation of PPP requires entering the storage temperature, information was collected from Deutscher Wetterdienst (http://www.dwd.de) and the temperature values for Sacramento (USA) were obtained from the National Climatic Data Center (http://cdo.ncdc.noaa.gov/climatenormals/clim20/ $\mathrm{ca} / 047630$.pdf).Three possible values were considered for the application of the equation: the recorded high temperature, the recorded low temperature, and the average temperature. The two first values were calculated on a monthly basis, while the average value was calculated considering the hour-byhour information. Figure 5 shows the plots obtained after applying the predictive model for $\%$ PPP with three temperatures (the average, the maximum average and the minimum average) in the two cities. The 
EVOO stored in Sacramento (California, USA) does not reach \% PPP higher than $17 \%$ in one year when the temperature is measured on an hourly basis with the average values given by National Climatic Data Center (Figure 5a). When the model is applied on a monthly basis with the maximum average temperature of each month, the limit of 17\% PPP is reached in six months but these extreme conditions have scarce possibilities of being real (Figure 5a). On the contrary, \% PPP would be very low $(<4 \%)$ if the monthly minimum average temperatures are the inputs of the mathematical model. These results show that EVOO stored in California should be strictly controlled and protected from higher temperatures and that action should be requested by consumer associations that pay for a virgin olive oil with a controlled quality. It is important to note, however, that those oils with high \% PPP may still be qualified as EVOO according to the sensory assessment and other quality parameters for all the other international regulatory bodies (IOC, EU, Codex Alimentarius, USA).

A very different situation is the storage of the same EVOOs in Frankfurt, where winters and summer are much cooler. Figure $5 \mathrm{~b}$ shows that \% PPP would be lower than $17 \%$ according to the simulation model. Taking into account an intermediate situation between Sacramento and Frankfurt, a shelf-life period of 18-24 months, from olive oil producing (not from olive oil bottling), would be appropriate enough for establishing a "Best before" date. The main conclusion is that the increment in \% PPP mostly depends on the temperature of the whole period of storage from the producer to the consumer.

The method for controlling \% PPP is not, however, easily implemented in all laboratories despite the effort made by researchers (Gertz and Fiebig, 2006) to simplify the initial procedure (MínguezMosquera et al., 1992). The request for rapid methods to detect virgin olive oil freshness is widely claimed by producers, sellers and consumers (Aparicio et al., 2013), and it obviously includes the determination of all the parameters that evolve over time, such as pigments.

\subsection{Mathematical model based on the pigment fluorescence bands for assistance in freshness prediction.}

Fluorescence spectroscopy meets the requirements of being rapid and simple and its application in determining pigments is scientifically supported since associated bands were produced (Figures 3 and 4). However, the selection of wavelengths that explain the decrease or increase of pigments associated with time and temperature of EVOO storage is not a simple exercise due to the complexity of the spectra and the number of compounds that may emit in the same region (Tena et al., 2012). Thus, the statistical procedures were applied to the whole range of the spectra collected at $\lambda_{\mathrm{ex}}=350 \mathrm{~nm}$, for sample 1 (var. Hojiblanca), which was selected as a training set. The selected wavelengths were verified with the spectra collected with sample 2 (a mix of var. Picual and var. Lechín), which played the role of validation set. Stepwise linear regression analysis (SLRA), under the strict Ridge Regression algorithm, was applied to the spectral intensities registered for 18 months, and the explaining variable was time (number of months). The statistical procedure selected three bands, 655, 680 and $695 \mathrm{~nm}$, which coincide with the zone of emission of pigments (Figure 3). The best regression in terms of adjusted- $\mathrm{R}^{2}$ was obtained for $655 \mathrm{~nm}$ (adjusted- $\mathrm{R}^{2}=0.91$ ), a wavelength that matches the distinctive band of pigments.

Despite the high value for an adjusted $-\mathrm{R}^{2}$ coefficient, the decrease in chlorophylls during storage follows a non-linear trend, as displayed in Figure 2. In fact, the evolution of $655 \mathrm{~nm}$ band showed a
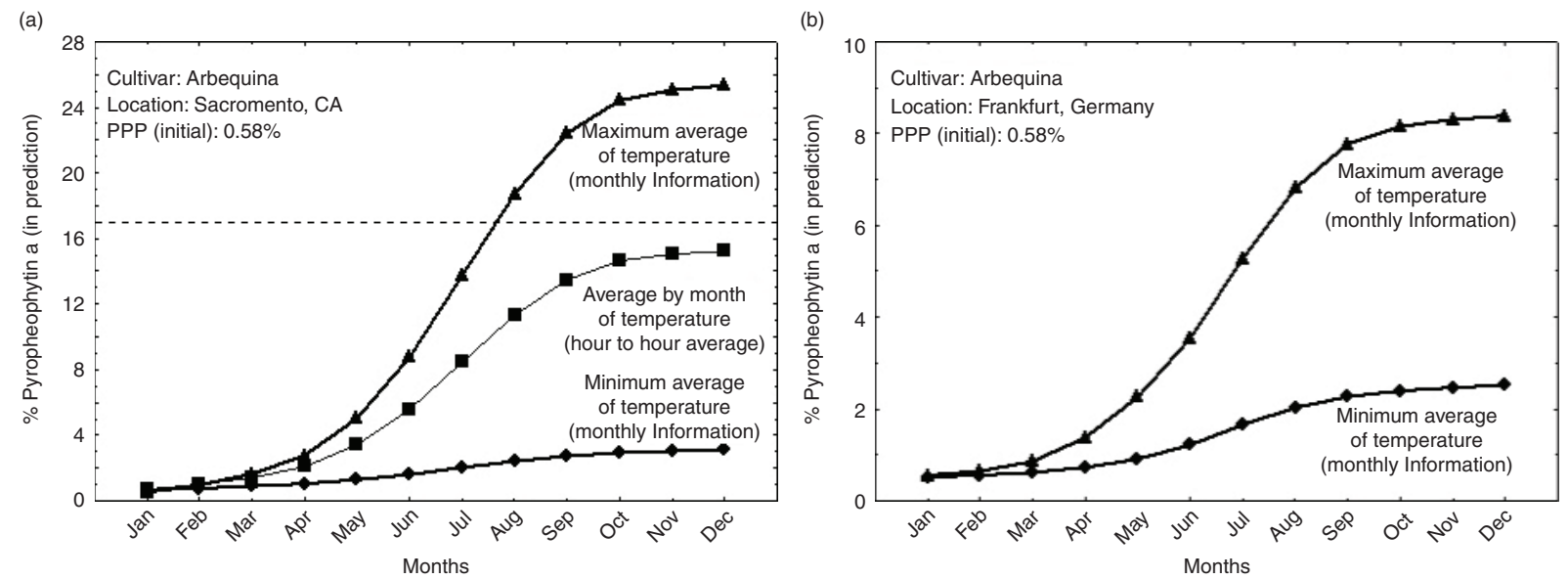

FIGURE 5. Prediction of the percentages of pyropheophytin a in accordance with the evolution of temperature based on monthly averages in Sacramento (a) and Frankfurt (b). 
non-linear trend during storage (Figure $6 \mathrm{~b}$ ), and a quadratic model was selected to relate the intensity $\left(\mathrm{I}_{\text {Kem } 655 \mathrm{~nm}}\right)$ of this band and the storage time (months).

$$
\begin{aligned}
\text { Time }(\text { month }) & =8.38-5.81 \times \mathrm{I}_{\text {Kem } 655 \mathrm{~nm}}+1.19 \\
\times\left(\mathrm{I}_{\text {Kem } 655 \mathrm{~nm}}\right)^{2} &
\end{aligned}
$$

Figure 6a shows the regression line of observed against predicted values of fluorescence intensity by the equation for a period of 18 months with the training and validation sets of data. The behavior of the results for training and validation sets are very similar, which could support the use of the strictest algorithm of Ridge Regression for building the model, but the use of the model with different cultivars and hence levels of pigmentation (Roca and MínguezMosquera, 2001) added uncertainty when predicting after 12 months (Figure 6a). This loss in certainty in prediction is not completely corrected after normalization by the initial values at $655 \mathrm{~nm}$ although some improvement is displayed in Figure $6 \mathrm{~b}$. As the model is based on a well-documented association of pigments and fluorescence signals (Tena et al., 2012), the problem of the loss in certainty in the last months can be found in the empirical effect of working with different cultivars. Thus, virgin olive oils may have similar values for their quality parameters but different levels of pigmentation, which influence the prediction between 14 and 18 months.

\section{CONCLUSIONS}

The two mathematical models described in this study highlight the use of pigments in the prediction of the shelf-life of extra virgin olive oil. The first mathematical model has pointed out the need to know the storage temperature from processing to the kitchen and the initial concentration of pyrophephytin to predict, in an accurate way, the shelf-life using a model based on the increment in PPP content. To guarantee an accurate prediction of the shelf-life based on this parameter, the shelflife must be predicted by taking into account the temperature in the place where the oil is going to be sold. The second mathematical model presented in this study was developed using the data obtained from a rapid and non-destructive technique that provides a rapid measurement of pigment content. This model was developed using the spectral region assigned to these compounds that clearly evolves during storage. The data treatment applied to the spectra of EVOOs acquired every month during 18 months selected a wavelength of emission at $655 \mathrm{~nm}$ as the best wavelength that correlates with the evolution of chlorophyll pigments during storage. The prediction formula has been successfully validated with the data obtained for another storage study using a EVOO sample of a different variety. Further research is currently being carried out to develop applications to assess freshness at industrial scale.

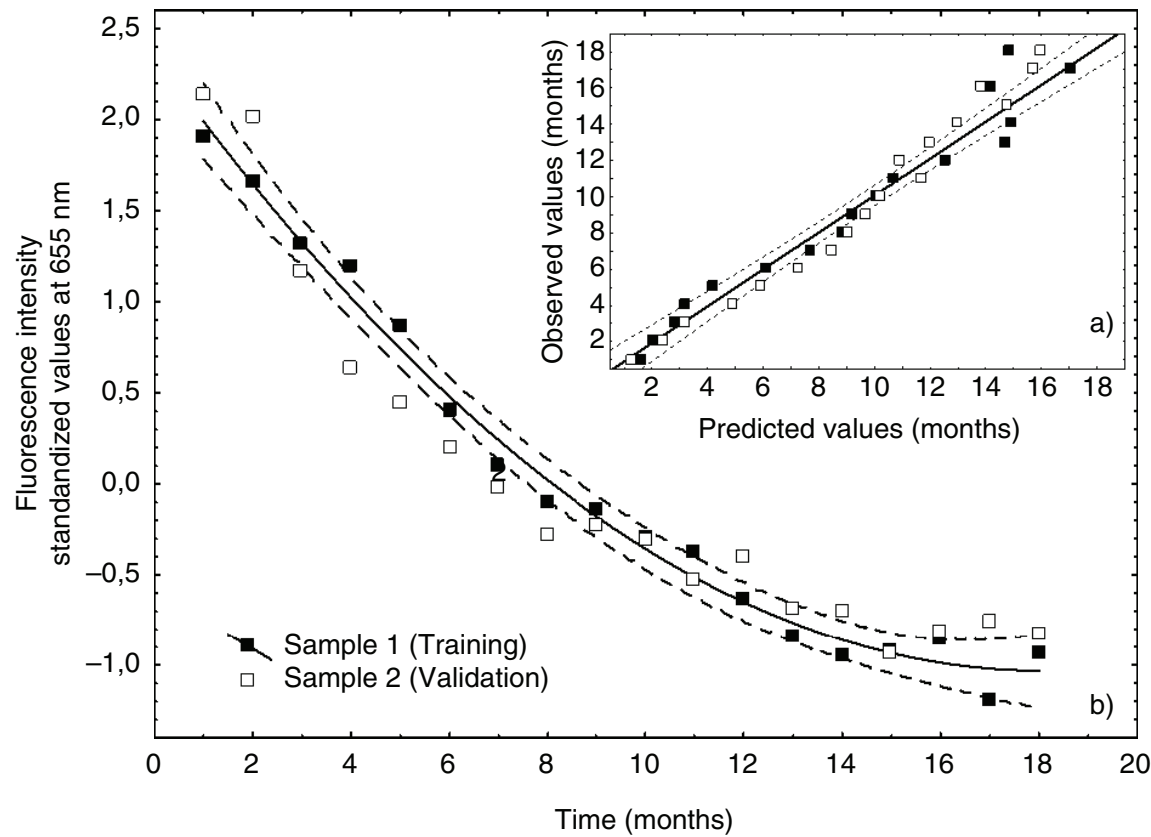

FIGURE 6. Relationship between observed and predicted values from the training and validation sets of data after applying the mathematical model (Figure 6a). Responses of the mathematical model for predicting months from bottling virgin olive oils based on the standardized value of fluorescence intensity at $655 \mathrm{~nm}\left(\lambda_{\mathrm{ex}}=350 \mathrm{~nm}\right)$ for training and validation data sets (Figure $6 \mathrm{~b}$ ). 


\section{ACKNOWLEDGEMENTS}

This work was supported by the Spanish State Secretary for Research, Development and Innovation (AGL2015-69320-R).

\section{REFERENCES}

Aparicio R, Morales MT, García-González DL. 2012. Towards new analyses of aroma and volatiles to understand sensory perception of olive oil. Eur. J. Lipid Sci. Technol. 114, 1114-1125. https://doi.org/10.1002/ejlt.201200193

Aparicio R, Morales MT, Aparicio-Ruiz R, Tena N, GarcíaGonzález DL. 2013. Authenticity of olive oil: Mapping and comparing official methods and promising alternatives. Food Res. Int. 54, 2025-2038. https://doi.org/10.1016/j. foodres.2013.07.039

Aparicio-Ruiz R, Aparicio R, García-González DL. 2014. Does "Best Before" date embody extra-virgin olive oil freshness? J. Agric. Food Chem. 62, 554-556. https://doi.org/10.1021/ jf405220d

Aparicio-Ruiz R, Mínguez-Mosquera MI, Gandul-Rojas B. 2010. Thermal degradation kinetics of chlorophyll pigments in virgin olive oils. 1. Compounds of series a. $J$. Agric. Food Chem. 58, 6200-6208. https://doi.org/10.1021/ jf9043937

Aparicio-Ruiz R, Roca M, Gandul-Rojas B. 2012. Mathematical model to predict the formation of pyropheophytin $a$ in virgin olive oil during storage. J. Agric. Food Chem. 60, 7040-7049. https://doi.org/10.1021/jf3010965

Australian Standards (AS) 2011. AS5264-2011: Olive Oils and Olive-pomace Oils. Committee FT-034.Sydney, Australia.

Ayton J, Mailer RJ, Graham K. 2012. The Effect of Storage Conditions on Extra Virgin Olive Oil Quality. Canberra (Australia): Rural Industries Research and Development Corporation (RIRDC) Publication, No. 12/024. https://1.oliveoiltimes.com/library/Olive-Oil-StorageConditions.pdf

California Department of Food and Agriculture (CDFA) 2016. Grade and Labeling Standards for Olive Oil, Refined-Olive Oil and Olive-Pomace Oil. Sacramento, 22 September 2016.

DeEll JR, Toivonen PMA. 1999. Chlorophyll fluorescence as an indicator of physiological changes in cold-stored broccoli after transfer to room temperature. J. Food Sci. 64, 501-503. https://doi.org/10.1111/j.1365-2621.1999.tb15071.x

Dupuy N, Le Dréau Y, Ollivier D, Artaud J, Pinatel C, Kister J. 2005. Origin of French virgin olive oil registered designation of origins predicted by chemometric analysis of synchronous excitation-emission fluorescence spectra. $J$. Agric. Food Chem. 53, 9361-9368. https://doi.org/10.1021/ jf051716m

Galeano Díaz T, Durán Merás I, Correa CA, Roldán B, Rodríguez Cáceres MI. 2003. Simultaneous fluorometric determination of chlorophylls $a$ and $b$ and pheophytins $a$ and $b$ in olive oil by partial least squares calibration. $J$. Agric. Food Chem. 51, 6934-6940. https://doi.org/10.1021/ jf034456m

Gallardo Guerrero L, Roca M, Gandul-Rojas B, Mínguez Mosquera MI. 2005. Effect of storage on the original pigment profile of Spanish virgin olive oil. J. Am. Oil Chem. Soc. 82, 33-39. https://doi.org/10.1007/ s11746-005-1039-8

Gertz C, Fiebig HJ. 2006. Pyropheophytin $\alpha$ - Determination of thermal degradation products of chlorophyll $a$ in virgin olive oil. Eur. J. Lipid Sci. Technol. 108, 1062-1065. https:// doi.org/10.1002/ejlt.200600164
International Olive Council (IOC). 2015. Sensory analysis of olive oil. Method for the organoleptic assessment of virgin olive oil. COI/T.20/Doc. No 15/Rev. 8. Madrid: Spain.

International Olive Council (IOC). 2016. Trade standard applying to olive oils and olive-pomace oils. COI/T.15/ NC No. 3 Rev.11, July 2016, Madrid, Spain.

ISO. International Organization for Standardization. 2009. ISO 660:2009, Animal and vegetable fats and oils Determination of acid value and acidity. Geneva, Switzerland.

ISO. International Organization for Standardization. 2007. ISO 3960:2007, Animal and vegetable fats and oils Determination of peroxide value - Iodometric (visual) endpoint determination. Geneva, Switzerland.

ISO. International Organization for Standardization. 2011. ISO 3656:2011, Animal and vegetable fats and oils Determination of ultraviolet absorbance expressed as specific UV extinction. Geneva, Switzerland.

Mínguez-Mosquera MI, Gandul-Rojas B, Garrido-Fernández J, Gallardo Guerrero, L. 1990. Pigment presence in virgin olive oil. J. Am. Oil Chem. Soc. 67, 192-196. https://doi. org/10.1007/BF02539624

Mínguez-Mosquera MI, Gandul-Rojas B, Gallardo-Guerrero L. 1992. Rapid method of quantification of chlorophylls and carotenoids in virgin olive oil by HPLC. J. Agric. Food Chem. 40, 60-63. https://doi.org/10.1021/jf00013a012

Morales MT, Przybylski R. 2013. Olive Oil Oxidation, in Aparicio R, Harwood J (Eds.) Handbook of Olive Oil. Analysis and Properties, second ed., Springer, New York. 479-522. https://doi.org/10.1007/978-1-4614-7777-8 13

Roca M, Mínguez-Mosquera MI. 2001. Changes in chloroplast pigments of olive varieties during fruit ripening. J. Agric. Food Chem. 89, 832-839. https://doi.org/10.1021/if0010001

South African National Standard (SANS) 2015. Olive Oils and Pomace Olive Oils. SANS1377:2015. (Government Gazette, 22 May, 2015, pag. 32 No. 38803). National Committee SABS. South Africa.

Sayago A, García-González DL, Morales MT, Aparicio R. 2007. Detection of the presence of refined hazelnut oil in refined olive oil by fluorescence spectroscopy. J. Agric. Food Chem. 55, 2068-2071. https://doi.org/10.1021/jf0618751

Schwartz SJ, Woo SL, von Elbe JH. 1981. High performance liquid chromatography of chlorophylls and their derivatives in fresh and processed spinach. J. Agric. Food Chem. 29, 533-535. https://doi.org/10.1021/jf00105a025

Sievers G, Hynninem PH. 1977. Thinlayer chromatography of chlorophylls and their derivatives on cellulose layers. J. Chromatogr. A 134, 359-364. https://doi.org/10.1016/ S0021-9673(00)88534-9

Sikorska E, Górecki T, Khmelinskii IV, Sokorski M, Koziol J. 2005. Classification of edible oils using synchronous scanning fluorescence spectroscopy. Food Chem. 89, 217-225. https://doi.org/10.1016/j.foodchem.2004.02.028

Tena N. 2010. Evolution of major and minor compounds in thermoxidized olive oils: Analyses by spectroscopic and chromatographic methodologies. Ph.D. Dissertation. University of Sevilla (Spain).

Tena N, Aparicio R, García-González DL. 2012. Chemical changes of thermoxidized virgin olive oil determined by excitation-emission fluorescence spectroscopy (EEFS). Food Res. Int. 45, 103-108. https://doi.org/10.1016/j. foodres.2011.10.015

Tena N, García-González DL, Aparicio R. 2009. Evaluation of virgin olive oil thermal deterioration by fluorescence spectroscopy. J. Agric. Food Chem. 57, 10505-10511. https:// doi.org/10.1021/jf902009b

Zandomeneghi M, Carbonaro L, Caffarata C. 2005. Fluorescence of vegetable oils: olive oils. J. Agric. Food Chem. 53, 759-766. https://doi.org/10.1021/jf048742p 